\title{
Optimization of Tax Collection and Administration Efficiency in Less Developed Regions of Western China
}

\author{
Ke Yan, ${ }^{1,2}$ Min Zuo $\mathbb{D}^{1,2}$ Hao Zhang $\mathbb{D}^{1},{ }^{2}$ Yuanyuan Gong $\mathbb{D D}^{2}$ and Jiaqi Fang ${ }^{3}{ }^{3}$ \\ ${ }^{1}$ National Engineering Laboratory for Agri-Product Quality Traceability, Beijing Technology and Business University, \\ Beijing 100048, China \\ ${ }^{2}$ School of E-Business and Logistics, Beijing Technology and Business University, Beijing 100048, China \\ ${ }^{3}$ School of Business, Wenzhou University, Wenzhou 325000, China \\ Correspondence should be addressed to Hao Zhang; zhhaozhhao@126.com and Jiaqi Fang; 82010561@qq.com
}

Received 23 November 2021; Accepted 21 December 2021; Published 24 January 2022

Academic Editor: Daqing Gong

Copyright (C) $2022 \mathrm{Ke}$ Yan et al. This is an open access article distributed under the Creative Commons Attribution License, which permits unrestricted use, distribution, and reproduction in any medium, provided the original work is properly cited.

\begin{abstract}
Tax is the main source of national and regional income, and the efficiency of tax collection and administration is of great significance to the sustainable development. In order to improve the efficiency of tax collection and administration in the less developed regions of western China due to the slow economic development, the low volume of tax revenue, and the high cost of tax collection and administration, this study extends the two-stage DEA model to the case of asymmetric two-stage efficiency values and analyzes the tax collection and administration efficiency of Yunnan Province by the improved model. The results show that the average value of tax collection and administration efficiency of Yunnan Province in 2020 is 0.944, and the overall efficiency values of tax collection and administration in most of the states and cities are within the range of 0.8-1.0. The overall tax collection and administration efficiency of Yunnan Province is relatively ineffective and can be improved. This study also makes relevant suggestions on how to improve the efficiency of organizations to promote the sustainable development of regions and the nation.
\end{abstract}

\section{Introduction}

At the early stage of the founding of China, the economic base was weak, and according to the complex actual situation at home and abroad at that time, the Chinese government established the economic system. Government departments have focused too much attention on the issue of total tax revenue growth for a long period of time, but the issue of tax collection and administration efficiency has not received sufficient attention.

The original fiscal and taxation system that had been in place also revealed more and more defects. In order to comply with the economic development of the new era, the establishment of a socialist market economy was proposed at the 14th Communist Party Congress to promote the rapid development of China's economy and society in 1992. Along with the tax reform and separation of taxation authority implemented in China since 1994 to meet the development of the economy in the new era, the local tax revenue has become the main source of revenue for the nation and regions. The tax revenue organized by the national taxation department reached 13.68 trillion RMB in 2020, 26.98 times the 1994 tax revenue of 507 billion RMB, with an average annual growth rate of $1.03 \%$. However, due to the lack of local tax sources and excessive local tax incentives, local tax revenues can hardly meet the financial expenditures of local governments, and the cost of tax collection and administration by local governments remains high. The average cost of overall tax collection in China still reaches about $4 \%$, and there is still a big gap compared with less than $2 \%$ in developed Western countries, such as $0.6 \%$ in the United States, $0.95 \%$ in Singapore, $1.07 \%$ in Australia, $1.76 \%$ in the UK, and $1.9 \%$ in France. In addition, the cost of tax collection and administration in the relatively backward cities in the eastern coastal regions of China, as well as the lessdeveloped western regions whose economy lags behind that of the eastern coastal regions, is much lower than the average level in China, for example, $4.3 \%$ in Shandong and $4.7 \%$ in Guangdong; the less-developed regions in the west are relatively high, such as 9.6\% in Inner Mongolia and 11\% in 
Guizhou, and the relevant government departments in the less-developed regions should pay more attention to this serious reality and take active measures to improve the efficiency of local tax collection and administration.

The concept of less-developed regions has both narrow and broad distinctions; in the narrow sense, on the one hand, it refers to the relatively underdeveloped regions within the various regions of a country. On the other hand, it encompasses both the narrow sense and the concept of countries with relatively underdeveloped economies on a large global scale, such as developed versus developing countries as for the broader concept. There is also some difference in the definition of the concept of less-developed regions by domestic and foreign researchers. Todaro [1] finds that the less-developed region is characterized by three main aspects based on the study of the laws of economic growth and the interrelationship of social processes, i.e., the relatively low standard of living of people, the general lack of self respect of residents, and the limited freedom enjoyed by residents. Meanwhile, the less developed region is characterized economically by low-income levels, low labor productivity, and high unemployment and underemployment. Todaro's statement on the substantive characteristics of lessdeveloped regions is generally accepted by a wide range of scholars as an important basis for distinguishing whether the region is classified as less developed or not.

A large number of researchers in China have distinguished the less-developed regions in the country mainly from the perspective of geographic regions, economic development, and statistical methods. According to the Seventh Five-Year Plan, China's economic zones are geographically divided into three major zones, i.e., the eastern, central, and western zones. The developed regions including 12 provinces, cities, and autonomous regions, i.e., Beijing, Tianjin, Hebei, Liaoning, Shanghai, Jiangsu, Zhejiang, Fujian, Shandong, Guangdong, Guangxi, and Hainan in the east, the less developed regions including Shanxi, Inner Mongolia, Jilin, Heilongjiang, Anhui, Jiangxi, Henan, Hubei, and Hunan, and the underdeveloped areas including Sichuan, Guizhou, Yunnan, Tibet, Shaanxi, Gansu, Ningxia, Qinghai, and Xinjiang. According to some research focusing on the factors that contribute to the current situation of regional development imbalance in China and the relationship between regional development imbalance and the modernization process, Shanghai, Beijing, and Tianjin have been defined as economically developed regions. Guangdong, Jiangsu, Zhejiang, Liaoning, Fujian, and Shandong are classified as more economically developed regions. Hainan, Shanxi, Jilin, Heilongjiang, Hebei, Guangxi, Hubei, Anhui, Hunan, Jiangxi, Henan, and Sichuan are classified as less economically developed regions, and Xinjiang, Tibet, Inner Mongolia, Qinghai, Guizhou, Gansu, Shaanxi, Ningxia, and Yunnan are classified as economically backward regions. The less-developed regions in this study are the 12 provinces and cities in the west of China whose regional economic development rate, productivity, and human resource capacity are relatively lagging behind those of the central and eastern cities.

The above examples show that tax is an important source of income for regions and countries, that plays an important role in the sustainable development of the regional economy; especially, the level of economic development between regions is unbalanced in China. For less-developed regions, it is more urgent to improve the efficiency of tax collection and administration through scientific means. Although the efficiency of tax collection and administration has attracted the attention of scholars, there are few literature studies to establish the corresponding evaluation index system according to the actual situation of underdeveloped regions of China and select the appropriate data analysis method to evaluate the efficiency of tax collection and administration. To fill up the above research gap, this study studies the tax collection and administration efficiency of China's economically underdeveloped areas, by optimizing the substage weight values of the two-stage DEA model, and puts forward relevant suggestions for the government and other organizations combing with the research results.

This study is organized in the following ways: In Section 2 , this study concludes the related research and proposes research gap. In Section 3, this study introduces the improved two-stage DEA model. In Section 4, this study constructs the efficiency evaluation index system and conducts empirical research. In Section 5, this study concludes the study and makes suggestions.

\section{Literature Review}

Most of the scholars focused on the research of taxation ideas and theoretical perspectives. In this regard, Petty [2] analyzed the economic instability of England, the confusion of the taxation system, and the heavy taxation that were not conducive to the healthy and effective development of the economy, and proposed the taxation principle of "fairness, simplicity, and economy" in view of the economic situation. Turgot [3] focused on the formation of social wealth and the distribution of income as well as discussed the advantages and disadvantages of direct and indirect taxes. He put forward the abolition of tax exemptions for nobles and others in order to achieve equal taxation. To summarize a large number of previous scholars' research results, Smith [4] put forward the four major taxation principles of "equality, certainty, convenience, and least cost." The least cost means that the state taxation department should minimize the cost of taxation, which also laid the foundation for the principle of efficiency proposed by western taxation scholars later.

With the huge financial pressure for the western countries in the 20th century, how to manage a large amount of underground economy and reduce the fiscal deficit effectively is urgent, so a large of research focusing on tax collection and administration efficiency have been gradually improved. The related research is not only limited to the tax system and theoretical perspective but also from the practical perspective of increasing the cooperation of different tax authorities, strengthening publicity to enhance taxpayer compliance, etc. More practical suggestions are put forward to improve the efficiency of tax collection and administration. Musgrave [5] summarized the classical taxation principles and proposed the famous six principles as well as reduced the cost of tax administration and collection as much as possible and the tax burden on government departments. In addition, he put forward a series of incentives 
to encourage taxpayers to pay taxes voluntarily in order to eliminate the negative impact on the economy. Based on the theory of tax evasion, Dhami and Al-Nowaihi [6] constructed a static tax evasion model to conclude that whether a taxpayer would choose to evade tax is mainly influenced by the dynamics of both the cost of tax compliance and the potential benefits of tax evasion. Influenced by the classic tax evasion model, the research on tax administration has been expanded to the field of tax compliance, e.g., the role of social factors such as morality, ethos, and credibility on public tax compliance. For example, Alm et al. [7] analyzed the phenomenon that the expected benefits from tax evasion by taxpayers remained high, but the true rate of tax evasion was low that cannot be explained by expectancy theory. They proposed that people's expected probability of being punished for tax evasion was much greater than the probability of its true occurrence by prospect theory. In addition, Bergman [8] compared the growth rate of government revenue between Chile and Argentina after the implementation of tax system reform and pointed out that the stability of tax policy has a strong influence on taxpayers and can effectively improve taxpayers' compliance.

Moreover, some studies focused on the efficiency of tax collection and administration from a different perspective. With the acceleration of globalization, many countries have been affected by macroeconomic and a series of other factors, and the politicians need to compare the tax policies of different countries horizontally to adjust their own tax collection policies constantly. Nguyen et al. [9] analyzed the performance of tax administration for 44 countries by both semi-nonparametric StoNED and conditional order-m methods. They found that the efficiency of the 2012-2015 time is significantly higher than that of the 2008-2011 period. Considering the environment tax to reduce pollution and improve energy efficiency, measure-data envelopment analysis, He et al. [10] analyzed the impact of energy efficiency on environmental pollution by conducting the empirical analysis for 32 OECD countries with the panel data. They found that the energy tax can improve energy efficiency without considering undesired outputs, and changes in energy prices, environmental technologies, and the energy mix have an important effect on energy efficiency and suggest the corresponding improvement measures. Additionally, the DEA model is widely used in efficiency analysis, etc., [11]; for example, Dahooie et al. [12] combined the DEA and MADM to evaluate the consumer credit risk with considering the undeniable impact of time and changes of the credit assessment criteria. They proposed a new method to determine the final aggregated rank, which has been able to maintain robustness. With respect to the accounting and financial indicators of 124 OECD countries, Wanke et al. [13] combined DEA and SFA to resolve the underlying relationships so that efficiency scores can be properly computed. Moreover, some studies focus on the efficiency to conduct research by the two-stage DEA model; for example, Chen et al. [14] studied the operating efficiency of universities considering the shared input resource. Then found that one third of 52 selected universities were efficient by considering the teaching and research process and suggested that the government should adjust the financial allocation mechanism to improve the efficiency. With respect to the land waste unsustainable problems, Jingxin et al. [15] analyzed the efficiency of the construction and production stage of urban construction land use. They put forward that the government should strengthen the coordination among cities. Considering the water consumption and discharge, Wang et al. [16] studied the efficiency of the overall, water used, and decomposed stage based on the game cross efficiency two-stage DEA model. They found that the utilization rate of water resources in the eastern region was higher, and the wastewater treatment efficiency in the western region was higher. Meanwhile, they put forward relevant suggestions for China's sustainable development.

Through the above research review, there is little research on the efficiency of tax collection and administration in less-developed areas in Western China. In addition, there are some existing studies on tax collection and administration efficiency with the DEA model, but there are a few studies based on the multistage DEA model to focus on the impact of two substages and the impact of intermediate input variables on the final efficiency. Moreover, this study extends the weight of the two substages to the asymmetric case based on the traditional DEA model to study the tax collection and management efficiency, which will be more in line with the actual situation. With the lagging economic growth, small total tax revenue, and low tax collection and administration efficiency in western underdeveloped areas of China, this study selects Yunnan Province as the empirical research object and improves the corresponding efficiency evaluation index system. In addition, this study analyzes the tax revenue, tax collection and administration policies, and regulations of Yunnan Province with the improved twostage DEA model. Then, this study analyzes and evaluates the calculation results to reveal the current situation of tax collection and administration of Yunnan Province, as well as put forward relevant countermeasures and suggestions to government departments so that the government departments can take a series of targeted measures according to the actual situation to reduce the cost and improve the efficiency.

\section{The Model}

It is not necessary for a specific functional form of the object of the DEA model, using the values of the weight coefficients of input and output indicators as the coefficients to be obtained, which has obvious advantages in solving the reallife single-stage system with multiple inputs and multiple outputs at the same time. However, it is not simple singlestage production processes in reality but also complex production processes containing multiple stages and subsystems, so multistage DEA has been more and more widely used to evaluate the efficiency of intermediate production processes by fully comparing the obtained data. In the twostage DEA model, the output indicators of the previous production stage can be used as input indicators of the latter production stage. However, the indicators with relatively large efficiency values are selected in the classical two-stage DEA model; this study is based on a weighted summation to handle data with relatively large and small efficiency values. 
The related variables in the study are shown in Table 1 to be more clear.

This study establishes a complete production process containing multiple intermediate variables that can be divided into two production stages according to the actual situation and assumes that the output of this production process contains $j$ decision units (i.e., $D M U_{j}, 1 \leq j \leq s$ ). Each $D M U_{j}$ is influenced by $m$ input indicators, $l$ intermediate output indicators (outputs according to $m$ input indicators), and final output indicators $n$. The input and output processes in this production process are shown in Figure 1.

This study assumes $\quad X_{j}=\left(x_{1 j}, \cdots, x_{m j}\right)^{T}$,
$Y_{j}=\left(y_{1 j}, \cdots, y_{s j}\right)^{T}, Z_{j}=\left(z_{1 j}, \cdots, z_{l j}\right)^{T}, \alpha=\left(\alpha_{1}, \cdots, \alpha_{m}\right)^{T}$, $X_{0}=X_{j 0}, \quad Y_{0}=Y_{j 0}, \quad Z_{0}=Z_{j 0}, \quad U=\left(u_{1}, \cdots, u_{m}\right)^{T}$, $V=\left(v_{1}, \cdots, v_{n}\right)^{T} W=\left(w_{1}, \cdots, w_{l}\right)^{T}, e=(1, \cdots, 1)^{T} . X_{j}, Y_{j}$, and $Z_{j}$ are expressed as the vector of initial input indicators, the vector of final output indicators, and the vector of intermediate indicators (i.e., the vector of primary output and secondary input indicators) for $D M U_{j}$, respectively; these three indicator vectors can be obtained from actual surveys. $\alpha$ is the relative weight of the first production stage and the second production stage; this paper assumes $\alpha=0.5$ based on the statistics of previous years. All the identified input indicators can be split into two stages for the analysis; $\alpha X_{j}$ represents the inputs of the first subproduction system, and the remainder of the input indicators $(e-\alpha) X_{j}$ represents the local inputs of the second-stage subproduction system. In the subproduction system of the first stage, the weight vector is represented by $U \in E^{m}$ and $W \in E^{l}$. According to the traditional fractional programming, this study concludes the two fractional programming problems as follows:

$$
\begin{aligned}
& \max \frac{W^{T} Z_{0}}{U^{T}\left(\alpha \bullet X_{0}\right)}, \\
& \text { s.t. } \quad \frac{W^{T} Z_{j}}{U^{T}\left(\alpha \bullet X_{j}\right)} \leq 1, j \in J \\
& 0 \leq \alpha \leq e \\
& U \geq 0, W \geq 0 \\
& U \bullet \alpha \neq 0 .
\end{aligned}
$$$$
\begin{array}{lc}
\max & \frac{V^{T} Y_{0}}{U^{T}\left((e-\alpha) \bullet X_{0}\right)+W^{T} Z_{0}} \\
\text { s.t. } & \frac{V^{T} Y_{j}}{U^{T}\left((e-\alpha) \bullet X_{j}\right)+W^{T} Z_{j}} \leq 1, j \in J
\end{array}
$$$$
0 \leq \alpha \leq e
$$$$
U \geq 0, W \geq 0, V \geq 0
$$$$
(U \bullet(e-\alpha), W) \neq 0 \text {. }
$$

ollows:

The equivalent linear programming problems are as

$$
\begin{aligned}
& \max \quad \omega_{1}^{T} Z_{0} \\
& \text { s.t. } \quad \mu_{1}^{T}\left(\alpha \bullet X_{j}\right)-\omega_{1}^{T} Z_{j} \geq 0, j \in J \\
& \mu_{1}^{T}\left(\alpha \bullet X_{0}\right)=1 \\
& 0 \leq \alpha \leq e, \mu_{1} \geq 0, \omega_{1} \geq 0 . \\
& \max \quad \delta_{2}^{T} Y_{0} \\
& \text { s.t. } \quad \mu_{2}^{T}\left((e-\alpha) \bullet X_{j}\right)+\omega_{2}^{T} Z_{j}-\delta_{2}^{T} Y_{j} \geq 0, j \in J \\
& \mu_{2}^{T}\left((e-\alpha) \bullet X_{j}\right)+\omega_{2}^{T} Z_{0}=1 \\
& 0 \leq \alpha \leq e, \mu_{2} \geq 0, \omega_{2} \geq 0, \delta_{2} \geq 0 .
\end{aligned}
$$

Considering the importance of the two production substages in the whole production process, this study can determine the specific weight values of the two stages according to the requirements of the actual situation. According to the characteristics of the object of our study, the subproduction system problems of the first and second stages are considered simultaneously, and this study constructs the improved DEA model of the fractional planning problem with multiple solution objectives as follows:

$$
\begin{aligned}
& \max a \frac{W^{T} Z_{0}}{U^{T}\left(\alpha \bullet X_{0}\right)}+(1-a) \frac{V^{T} Y_{0}}{U^{T}\left((e-\alpha) \bullet X_{0}\right)+W^{T} Z_{0}} \\
& \text { s.t. } \frac{V^{T} Y_{j}}{U^{T}\left((e-\alpha) \bullet X_{j}\right)+W^{T} Z_{j}} \leq 1, j \in J \\
& U \geq 0, W \geq 0, V \geq 0,0 \leq \alpha \leq e \\
& U \neq 0, \alpha \neq 0,(U \bullet(e-\alpha), W) \neq 0 .
\end{aligned}
$$

\section{Empirical Analysis}

The process of tax collection is actually an input-output process. The government controls the tax collection and administration efficiency mainly according to the direction of tax inspection and assessment. For example, the "Tax Collection and Management Quality Assessment Measure" promulgated by the General Administration of Taxation of China in 1999, including the declaration rate, registration rate, deposit rate, tax arrears increase or decrease rate, late payment increase rate, and penalty rate. Meanwhile, many researchers have selected indicators such as the tax collection cost, growth rate, and elasticity coefficient to carry out research through various quantitative and qualitative research methods. The corresponding input indicators, intermediate indicators, and output indicators are selected according to the input-output principle of the two-stage DEA model, as shown in Table 2.

As for the input indicator, the number of tax revenue plans means that the taxation authorities measure the actual tax revenue based on the local economic development for a 
TABLE 1: The notations.

\begin{tabular}{lc}
\hline Notation & Explanation \\
\hline$x_{i j}=D M U_{j}, x_{i j}>0, i=1,2, \cdots, m$ & The amount of input indicator $i$ \\
$y_{r j}=D M U_{j}, y_{r j}>0, r=1,2, \ldots, n$ & The amount of final output indicator $r$ \\
$z_{k j}=D M U_{j}, z_{k j}>0, k=1,2, \cdots, l$ & The amount of intermediate indicator $k$ \\
$\alpha_{i}, 0<\alpha_{i} \leq 1, i=1,2, \cdots, m$ & The ratio of input indicator $i$ in the first stage \\
$u_{i}=D M U_{j}, i=1,2, \cdots, m$ & The weight of indicator $i$ \\
$v_{r}=D M U_{j}, r=1,2, \cdots, n$ & The weight of indicator $r$ \\
$w_{k}=D M U_{j}, k=1,2, \cdots, l$ & The weight of indicator $k$
\end{tabular}

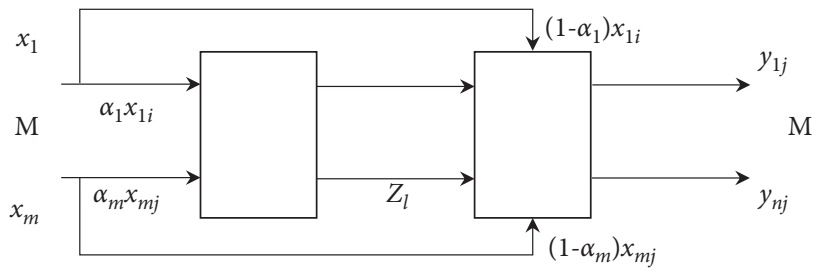

Figure 1: Production flowchart of the decision unit $D M U_{j}$.

certain period of time, and the regional taxation departments will make work plans based on this plan and compare them at the end of the year. The average annual wage of each state and city reflects the condition of the local economy as well as an important source of tax revenue. The number of employees means the equilibrium point of labor supply and demand and the important guarantee of tax revenue, as well as a source of generation of intermediate stage indicators.

With respect to the intermediate indicator, the proportion of secondary and third industries in GDP means the tax actually acts as a small part of GDP, while there are changes in the scale of China's macroindustrial structure and also determines the source and total amount of regional tax revenues. Since the abolition of the agricultural tax in 2006, the amount of tax levied on the primary industry has been very small, so the original value added to the secondary and third industries can represent the number of tax sources better. The proportion of business balance in GDP means the value added and created by residents minus the sum of workers' compensation, net production tax, and depreciation of fixed assets as the good indicator of the degree of economic development for the region, as well as the more intuitive reflection of the quality of tax revenue sources for relevant government departments. The proportion of net production tax in GDP has a significant impact on the total tax revenue, which can represent the magnitude of the impact more graphically.

In terms of output indicator, the tax revenue means the final actual amount of tax revenue of the country or region, and it can be used as an important indicator for the efficiency of tax collection and administration of government departments.

According to the two-stage DEA model, this study constructs the input-output model of tax collection and administration, and processes the data of the above index system to evaluate the results of tax collection and administration efficiency of each state and city in Yunnan Province, as shown in Table 3.
The lower overall level of economic development generally lags behind the central and western regions resulting in fewer sources of tax revenue for the western region of China. This study concludes that the overall tax collection efficiency of Yunnan Province is 0.944, and the average values of first and second-stage efficiency are 0.972 and 0.916 , respectively, which are relatively inefficient, indicating that there is still much room for improving the overall tax collection and administration efficiency. In addition, the level of economic development has a significant impact on the efficiency of tax collection and administration; for example, the higher GDP in Kunming and Yuxi leads to a more adequate number of tax sources, a better quality of tax sources, and stronger tax-paying ability; thus, the efficiency of tax collection and administration is also more forward. With the reform of some governmental tax policies and the construction of a standardized system of tax administration, the promotion of integrated management of fees and taxes, and the solution of the problem of unsynchronized payment of fees and taxes have enhanced the efficiency of local tax collection and administration greatly, for example, Dali 0.959 and Lijiang 0.965 , which are worth learning from other states and cities in Yunnan Province.

In addition, this study gives the following suggestions on how to take effective measures to improve the efficiency as follows: (1) promoting economic development vigorously narrows the gap between the less-developed western regions and the central as well as eastern regions. According to different geographical advantages, resource advantages, technological advantages, and other resources, the government should develop the secondary and third industries suitable for their provinces and cities according to local conditions so as to promote economic growth rapidly and create a large number of employment opportunities and per capita wage income for residents, thus promoting the substantial increase in total tax revenue. (2) According to the structure of China's three major industries adjusted with the development of society continuously, the local government 
TABLE 2: Evaluation index system of tax collection and administration efficiency.

\begin{tabular}{lc}
\hline Indicator & Content \\
\hline Input indicator & $\begin{array}{c}\text { Number of tax revenue plans } \\
\text { Average annual wage of each state and city } \\
\text { Number of employees }\end{array}$ \\
\hline Intermediate indicator & $\begin{array}{c}\text { Proportion of secondary industry in GDP } \\
\text { Proportion of third industry in GDP } \\
\text { Proportion of business balance in GDP } \\
\text { Putput indicator }\end{array}$ \\
\hline
\end{tabular}

TABLE 3: Evaluation results.

\begin{tabular}{|c|c|c|c|c|}
\hline Region and state & Total efficiency & Efficiency of first stage & Efficiency of second stage & Rank \\
\hline Kunming & 1.000 & 1.000 & 1.000 & 1 \\
\hline Qujing & 0.934 & 1.000 & 0.868 & 9 \\
\hline Yuxi & 0.977 & 1.000 & 0.954 & 3 \\
\hline Baoshan & 0.901 & 0.933 & 0.868 & 14 \\
\hline Zhaotong & 0.894 & 1.000 & 0.788 & 16 \\
\hline Lijiang & 0.965 & 0.930 & 1.000 & 6 \\
\hline Puer & 0.959 & 0.917 & 1.000 & 8 \\
\hline Lincang & 0.898 & 1.000 & 0.797 & 15 \\
\hline Chuxiong & 0.920 & 1.000 & 0.840 & 12 \\
\hline Honghe & 0.910 & 1.000 & 0.819 & 13 \\
\hline Wenshan & 0.971 & 1.000 & 0.941 & 5 \\
\hline Xishuangbanna & 0.974 & 1.000 & 0.948 & 4 \\
\hline Dali & 0.959 & 0.918 & 1.000 & 7 \\
\hline Dehong & 0.931 & 0.861 & 1.000 & 10 \\
\hline Nujiang & 0.920 & 1.000 & 0.841 & 11 \\
\hline Diqing & 0.993 & 1.000 & 0.986 & 2 \\
\hline
\end{tabular}

departments should adjust tax incentives and exemptions to attract more investment. In addition, the governments should unify and standardize the relevant procedures and requirements, and give full play to the positive role of tax incentives in stabilizing growth so that they promote reform and benefit people's livelihood in the local society and economy. (3) The local governments should set up taxes scientifically according to the actual situation and divide tax types and tax powers reasonably. Moreover, the governments should promote the tax reform, optimize policies related to agricultural value-added tax, as well as the process of import and export tax rebates and refunds. (4) The government departments should increase the propaganda of paying taxes according to the law through more media so that taxpayers can fully understand the source of taxes and the ultimate use of taxes so as to enhance the tax compliance of the majority of taxpayers. In order to promote sustainable economic growth better, the governments should enhance the transparency of tax collection and use, counteract the resistance of taxpayers as much as possible, improve the distance between tax organizations and taxpayers, and improve the efficiency of tax collection and administration. (5) The related organizations should optimize the arrangement of departments and personnel to improve the performance appraisal mechanism and strengthen the connection between the national tax and local tax authorities so that they reduce the intermediate links, enhance linkage, as well as improve the work efficiency of tax departments. Meanwhile, they should strengthen the education and training of tax staff and stimulate the enthusiasm of staff and encourage them to work efficiently. (6) The government should strengthen the tax inspection and internal audit and crackdown on all kinds of tax-related violations severely. In addition, they should publish the information of major tax violations that meet the standards to the public through the portal website, announce the information of tax violations in the tax service office regularly, increase the transparency of law enforcement, and improve the credibility of law enforcement. (7) Optimizing the tax services is to promote modern tax services for the convenience and benefit of the public. Additionally, the government should integrate business processes, clarify taxpayers' exemption from filling out forms, improve online tax business continuously, and strive to achieve the most effective output with limited input.

\section{Conclusions and Discussion}

Although the current tax system of China has been relatively perfect, the tax system has been constantly revised according to the actual situation, and the instability of the tax system makes tax collectors constantly learn the latest relevant system, which not only consumes a lot of time but also requires a lot of relevant human and material resources. Moreover, the tax system changing and repairing constantly 
creates uneasiness of taxpayers, thus reducing tax compliance, and the instability of the tax system indirectly reduces the efficiency of tax collection and administration. There is still a certain crossover between tax types, and there are few sources of local tax revenue; especially for the less-developed regions in western China, the poor tax sources can hardly meet the demand for large fiscal expenditures. The low level of economic development, low overall education level, and imperfect tax collection and administration system seriously restrict the local tax revenue, so how to improve the tax collection and administration efficiency of taxation organizations effectively has become a daunting task for government departments for a long time in the future.

This study focuses on the cost of tax collection and administration of the government in the less-developed regions of western China higher than the average value in China, improves the efficiency of tax collection and management through scientific evaluation methods, and promotes the efficient development of backward areas. Firstly, according to the existing literature and the analysis of the actual tax collection and administration in the western lessdeveloped areas represented by Yunnan Province, this study improves the tax collection and administration efficiency evaluation index system as well as selects the corresponding initial investment, intermediate investment, and final index. Consequently, this study analyzes the traditional two-stage DEA model, sets the different weight values to optimize the model, and studies the tax collection and administration efficiency of Yunnan province based on the optimized model. Finally, the results show that the overall efficiency of tax collection and administration in Yunnan Province is relatively low, and there is still a lot of space for improvement. Due to the high level of economic development, Kunming also ranks first in the efficiency of tax collection and administration throughout Yunnan Province. According to the evaluation results of tax collection and administration efficiency, combing with the actual situation of Yunnan Province, this study puts forward seven suggestions for the government and relevant departments, hoping to promote the efficient development of tax collection in underdeveloped areas, set an example for other regions, and promote the sustainable and efficient development of China's economy.

This study is of great significance to the sustainable and stable growth of tax revenue as well as the harmonious development of society in all regions of China. However, there are still great limitations for the current research; for example, this study is mainly aimed at China's underdeveloped areas with a low level of economic development and less total tax revenue. Therefore, when the efficiency evaluation index system is applied to other provinces or countries, it may be necessary to adjust the indicator system more in line with the actual situation according to local conditions. In addition, with the change of the complexity of research objectives, the two-stage DEA used in this study may not well represent the causal relationship between indicators. Applying the three-stage DEA or the combination of DEA and other data analysis methods to study the tax collection and management efficiency is necessary.
Therefore, future research could consider the risk attitude of consumers and combine DEA with other measurement methods or data analysis means to research the tax collection and administration efficiency, or apply the improved twostage DEA model to focus on the other related efficiency evaluation. [15].

\section{Data Availability}

The data are available in the China National Statistical Yearbook.

\section{Conflicts of Interest}

The authors declare that they have no conflicts of interest.

\section{Acknowledgments}

This research was supported by the Research Foundation for Youth Scholars of Beijing Technology and Business University and National Key Research and Development Program of China (No. 2021YFD2100605).

\section{References}

[1] M. P. Todaro, Economic Development in the Third World: An Introduction to Problems and Policies in a Global Perspective, Pearson Education, London, UK, 1977.

[2] W. Petty, A Treatise of Taxes and Contributions, Brooke, London, UK, 1769.

[3] A. R. J. Turgot, Reflections on the Formation and the Distribution of Riches, LM Publishers, Netherlands, 2019.

[4] A. Smith, The Wealth of Nations: An Inquiry into the Nature and Causes of the Wealth of Nations, Harriman House Limited, Petersfield, UK, 2010.

[5] R. A. Musgrave, Public Finance in Theory and Practice: A Study in Public Economy, McGraw-Hill, New York, NY, USA, 1959.

[6] S. Dhami and A. Al-Nowaihi, "Why do people pay taxes? Prospect theory versus expected utility theory," Journal of Economic Behavior \& Organization, vol. 64, no. 1, pp. 171-192, 2007.

[7] J. Alm, B. R. Jackson, and M. McKee, "Estimating the determinants of taxpayer compliance with experimental data," National Tax Journal, vol. 45, no. 1, pp. 107-114, 1992.

[8] M. S. Bergman, "Tax reforms and tax compliance: the divergent paths of Chile and Argentina," Journal of Latin American Studies, vol. 35, no. 3, pp. 593-624, 2003.

[9] T. T. T. Nguyen, D. Prior, and S. Van Hemmen, "Stochastic semi-nonparametric Frontier approach for tax administration efficiency measure: evidence from a cross-country study," Economic Analysis and Policy, vol. 66, pp. 137-153, 2020.

[10] P. He, Y. Sun, H. Shen, J. Jian, and Z. Yu, "Does environmental tax affect energy efficiency? An empirical study of energy efficiency in OECD countries based on DEA and Logit model," Sustainability, vol. 11, no. 14, p. 3792, 2019.

[11] S. Haider and P. P. Mishra, "Does innovative capability enhance the energy efficiency of Indian Iron and Steel firms? A Bayesian stochastic Frontier analysis," Energy Economics, vol. 95, Article ID 105128, 2021.

[12] J. H. Dahooie, S. H. R. Hajiagha, S. Farazmehr, E. K. Zavadskas, and J. Antucheviciene, "A novel dynamic credit risk evaluation method using data envelopment analysis 
with common weights and combination of multi-attribute decision-making methods," Computers \& Operations Research, vol. 129, Article ID 105223, 2021.

[13] P. Wanke, M. G. Tsionas, Z. Chen, and J. J. Moreira Antunes, "Dynamic network DEA and SFA models for accounting and financial indicators with an analysis of super-efficiency in stochastic frontiers: an efficiency comparison in OECD banking," International Review of Economics \& Finance, vol. 69, pp. 456-468, 2020.

[14] Y. Chen, X. Ma, P. Yan, and M. Wang, "Operating efficiency in Chinese universities: an extended two-stage network DEA approach," Journal of Management Science and Engineering, 2021.

[15] G. Jingxin, S. Jinbo, and W. Lufang, "A new methodology to measure the urban construction land-use efficiency based on the two-stage DEA model," Land Use Policy, vol. 112, Article ID 105799, 2022.

[16] M. Wang, Y. Huang, and D. Li, "Assessing the performance of industrial water resource utilization systems in China based on a two-stage DEA approach with game cross efficiency," Journal of Cleaner Production, vol. 312, Article ID 127722, 2021. 